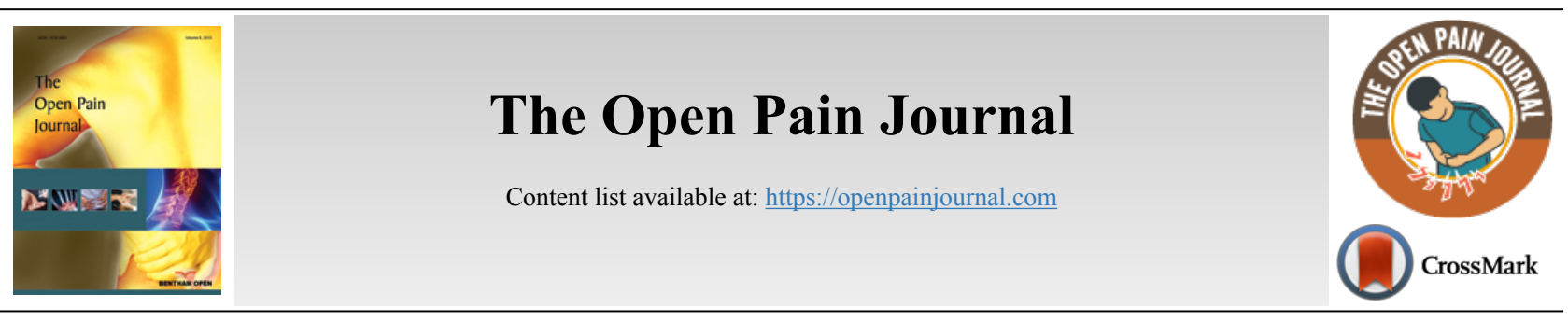

RESEARCH ARTICLE

\title{
Pharmacological Aspects of Phyllanthus fraternus Standardized Extract (Rich in Lignans and Tannins) as a Pain Modulator
}

\author{
Atul R. Chopade ${ }^{1, *}$, Pramod A. Patil ${ }^{1}$ and Suraj N. Mali ${ }^{2, *}$ \\ ${ }^{I}$ Department of Pharmacology, Rajarambapu College of Pharmacy, Kasegaon, Maharashtra, India \\ ${ }^{2}$ Government College of Pharmacy, Karad, Maharashtra, India
}

\begin{abstract}
:
Background:

The standardized extracts of $P$. fraternus were previously reported by us for its anti-inflammatory, analgesic, and anti-arthritic biological potentials. However, we have not reported for a consequence of $P$. fraternus on chronic inflammatory muscle hyperalgesia. Herein, we have demonstrated chronic pain modulating effect of standardized extracts of $P$. fraternus.
\end{abstract}

\section{Materials and Methods:}

Firstly, we have collected various parts of $P$. fraternus plant including the dried stems, leaves, and roots. In order to produce chronic inflammations, we further allowed injection to the left gastrocnemius muscle belly of rats with a freshly prepared solution of $3 \%$ carrageenan in normal saline $(100 \mu \mathrm{L})$. Thermal/heat hyperalgesia, mechanical hyperalgesia and muscle circumferences were determined in the current experimental model. In order to estimate, chronic pain modulating potential of $P$. fraternus, we have also studied histopathological studies and measurement of prostaglandin E-2 (PGE2).

Results:

After administration of $3 \%$ carrageenan intramuscular injection, we investigated the chronic thermal and mechanical hypersensitivity of aforementioned test sample i.e. standardized extracts of $P$. fraternus in terms of adopting 2 gradual dosings of $200 \mathrm{and} 400 \mathrm{mg} / \mathrm{kg}$ (administered intraperitoneally) from day $14^{\text {th }}$ to $22^{\text {nd }}$. From our study, we observed significant antihyperalgesic activity; when we allowed administering standardized extracts of $P$. fraternus intraperitoneally.

\section{Conclusion:}

To conclude, we have investigated the antihyperalgesic and anti-inflammatory potentials of standardized extracts of $P$. fraternus. These effects might be having mediation via supraspinal or spinal neuronal mechanisms, and mainly observed due to evidence of PGE2 inhibitions.

Keywords: P. fraternus, Carrageenan, Chronic muscle hyperalgesia, Gastrocnemius, Spinal neuronal mechanisms, Antihyperalgesic activity.

\begin{tabular}{|l|l|l|l}
\hline Article History & Received: March 10, 2020 & Revised: June 6, 2020 & Accepted: June 25, 2020
\end{tabular}

\section{INTRODUCTION}

Many clinically defined conditions occurring throughout the world are having major representing a symptom of pain originating from muscle [1]. In literature, a large number of experimental animal models were reported and investigated for pathological mechanisms of chronic pain for many years [2, 3]. Khanna et al., 2007 reported modulation of the expression of chronic pain inflammatory signals by plant based natural agents [3]. Various experimental and clinical studies have been

\footnotetext{
* Address correspondence to this author at the Rajarambapu College of Pharmacy, Kasegaon, Maharashtra, India; Tel: +91 9226346106;

E-mails: atulrchopade@gmail.com,mali.suraj1695@gmail.com
}

implemented and studied so far in order to investigate the roles of various Ayurveda and traditional medicinal plants for possible efficacy in chronic pain disorders [4]. A broad spectrum of pharmacological activities and medicinal properties has been demonstrated for phytoconstituents isolated from Phyllanthus fraternus Webster (Family: Euphorbiaceae) [5 - 15]. There has been a large number of scientific studies reported in traditional system of medicine for medicinal properties of various phyllanthus species [10 - 12]. For evaluating test compounds on chronic hyperalgesia induced by muscle inflammation, studies conducted by Radhakrishnan et $a l$. are found to be useful to give an animal model for same [13, 14]. It has also been proposed to have greater face validity to 
the pain of musculoskeletal origin arising in humans [14]. In our previous studies, we reported the potential of Phyllanthus amarus extracts as a chronic pain modulator [11]. Previously, we have also explored the anti-inflammatory, analgesic, anxiolytic and anti-arthritic potentials of standardized extracts of $P$. fraternus [10 - 12]. However, in our current study, we tried to explore the effects of $P$. fraternus on chronic inflammatory muscle hyperalgesia in terms of its chronic inflammatory pain modulation potentials.

\section{MATERIALS AND METHODS}

\subsection{Collection Details of $P$. Fraternus (Webster Family: Euphorbiaceae)}

The whole plant of $P$. fraternus (Euphorbiaceae) was collected from Karad tehsil situated in the state of Western Maharashtra, India. The identification and authentication of the plant of $P$. fraternus Webster[Reference No. BSI/WC/Tec./2012/644] were done by officials of Botanical Survey of India, Pune.

\subsection{Preparation of Standardized Extracts of P. Fraternus}

The shade dried plant components such as dried leaves, stems and roots were collected and further utilized in the current study. Further, these components were subjected for mincing and extraction with 70\% Ethanol:water (70:30 proportions). Then, we allowed the extracted marc to stir and further macerated at room temperature conditions $\left(22-28^{\circ} \mathrm{C}\right)$ for a period of 15 days. In order to get the desired semisolid level, we evaporated ethanolic portion and further concentrated the extract (yield 5-7\%) and stored in a refrigerator. We dissolved the standardized extract of $P$. fraternus in DMSO in order to achieve desired concentrations just before all experiments [13].

\subsection{Drugs and Chemicals}

A gift sample of Aceclofenac from Alembic Pharmaceuticals, Vadodara was utilised in the current study. Analytical solvents and necessary chemicals such as Carrageenan, anaesthetic ether, Potassium hydroxide, methanol and formalin were procured from a commercial source (Merck, Mumbai).

\subsection{Experimental Animals}

We have subjected male Wistar rats throughout the current study which were weighing approx. 200-340 g. We have taken precautions to feed animals with standard diet and water ad libitum. We have also maintained the necessary standard environmental conditions for them. Facilities and required things such as water and food were made freely available during the entire conduction of experiments. All necessary approvals for the current study were taken from the Animal Ethics Committee of Govt. College of Pharmacy, Karad (GCOPK) [Reference: CPCSEA / IAEC- 2012-MAR/01]. All necessary experiments were carried as per the guidelines suggested by CPCSEA for the care of laboratory animals and corresponding the ethical guidelines for animals as specified $[15,16]$.

\subsection{Induction of Chronic Inflammatory Muscle Hyperalgesia.}

To produce chronic inflammations in rats, we have made injections to the left gastrocnemius muscle belly with $(100 \mu 1)$ dose of $3 \%$ carrageenan in normal saline solution [14]. A spontaneous pain behavioural signals were witnessed in rats after 24 hours of post intramuscular injection of carrageenan. We have recorded the Paw withdrawal latencies (PWL'S) to stimuli such as heat and mechanical on daily bases in all groups considered under current study, after unstill the decrease in PWL's of the contra lateral paw (non carrageenan injected side) which was an indication of setting of the chronic model which consumed duration of 2 weeks [17].

\subsection{Experimental Protocol [Dosages of P. Fraternus Extract].}

The procedure described in above section 2.5 was used for induction of chronic inflammatory muscle pain in all the animals except normal control. In order to examine the pharmacological potential of $P$. fraternus extract on hypersensitivity (mechanical and thermal), we tried to administer all animals considered under this study with $P$. fraternus extract by subjecting them with intraperitoneal route from $14^{\text {th }}$ day to $22^{\text {nd }}$ day, after confirmation of chronic inflammatory pain $P$. fraternus extract was administered with approximately 12 hours apart for a period of 7 days twice a day. We have utilized Aceclofenac as a preferential COX-2 selective inhibitor as a standard at a dose of $10 \mathrm{mg} / \mathrm{kg}$, intraperitoneally was administered for comparison. The treatment was interrupted for two days such as on the $18^{\text {th }}$ and $19^{\text {th }}$ day. For assessment of the probable development of tolerance, we had reinitiated dosing again on $20^{\text {th }}$ day. After 60 to 80 minutes of the first day of treatment (the time when the maximal inhibition was seen during the acute treatment), we evaluated the nociceptive responses. Control groups (the hyperalgesic rats) were treated alone only with vehicle DMSO $0.2 \mathrm{ml}$ intraperitoneally and they were used for the comparative purpose along with the Aceclofenac and $P$. fraternus extract treated rats. For normal control, we have utilized healthy rats and kept parallel to another group of healthy rats, such as normal control was kept parallel to estimate the extent of muscle inflammation, foe differentiating histopathological features and changes in concentration of PGE2 after inflammation. Paw withdrawal latencies to heat and mechanical stimuli were observed and noted before carrageenan injection. Further, the recording of PWL'S to stimuli was continued until the end of the chronic study. For examination of the muscle histology at the site of injection, we sacrificed animals on the $22^{\text {nd }}$ day of the study [17].

\subsection{Evaluation of Thermal/Heat Hyperalgesia.}

Paw withdrawal latencies were determined by dipping the paw in the water bath maintained at $47^{\circ} \pm 1^{\circ} \mathrm{C}$ for recording the response to inflammatory hyperalgesia. Baseline latency was established thrice, $5 \mathrm{~min}$ apart and average was taken for statistical comparisons. To avoid any injury or damage to the paw, a cut-off time of 15 seconds was kept. While in the chronic model the paw withdrawal latency specifically for the 
contralateral paw was seen at a duration of 60-80 minutes after drug administration after subsequent dosing. We have recorded all responses to heat stimuli and they were measured before and post $3 \%$ carrageenan intramuscular injection till the end of current study on $22^{\text {nd }}$ day [17].

\subsection{Evaluation of Mechanical Hyperalgesia.}

First, all animals were subjected for placing them on an elevated metal grid for a period of $15 \mathrm{~min}$, so that they could adapt to their environment [14 - 17]. In order to produce mechanical stimuli, we used a series of von Frey nylon hairs or filament from 2-20 g, which were then applied in increasing force until there was the withdrawal of rat's hind paw. After simultaneous applications for 5 minutes, we assessed the presence of mechanical hyperalgesia for each hair and the threshold in grams $(\mathrm{g})$ was observed and recorded. For final readings, we noted the lowest force that causing minimum of 3 withdrawals out of 5 consecutive stimuli. We used to calibrate Von Frey nylon hairs throughout the entire study to ensure the consistency of bending forces of them. Von Frey stimuli generated mechanical responses were recorded for prior and post carrageenan intramuscular injection until there was the end of chronic study (till $22^{\text {nd }}$ day).

\subsection{Evaluation of Muscle Circumference}

Circumference in centimetres of inflamed and the noninflamed gastrocnemius muscle was measured after 14 days. It was measured by using a measuring tape over the skin of gastrocnemius muscle belly for confirming the initiation of inflammation and subsequent hyperalgesia. In all the subsequent groups after drug treatments, we measured the circumference of muscle for better assessment and correlation between the PWL'S and simultaneous inflammation. For muscle circumference measurement, we used to wrap the gastrocnemius muscle of each rat with the help of a piece of cotton thread around it and then further measurements with a metered ruler [14].

\subsection{Histopathological Studies}

After completion of each study, minimum of 2 animals from each group were sacrificed. $10 \%$ formalin solution was utilised for fixing their dissected ipsilateral knee joints as reported by Radhakrishnan et al.,2003 [14]. For sectioning the tissue, we used to do embedding for dissected gastrocnemius muscle in paraffin and same were further stained with hematoxylin and eosin ( $\mathrm{H}$ and $\mathrm{E})$. All sectioning were allowed to visualize under light microscopy. Pathologist helped us in a blinded fashion for analysis of histological findings, which were descriptive.

\subsection{Estimation of Prostaglandin E-2 (PGE2)}

Initially, to $2 \mathrm{~mL}$ of $\mathrm{KOH}$ :Methanolic $(0.5 \mathrm{~mol} / \mathrm{L})$ solution, we added $1 / 2 \mathrm{~mL}$ supernatant inflammatory immersion of the left muscle. After keeping for 20 min isomerization in a water bath at $50^{\circ} \mathrm{C}$, we further made the addition of methanol to a total capacity of $5 \mathrm{~mL}$. Thereafter, we mixed it thoroughly [16 - 18]. The absorbance was measured at $278 \mathrm{~nm}$ by utilization of Shimadzu 1800 UV spectrophotometer, after standing for 5 min. For an indication of PGE2 content, we have investigated with per $\mathrm{ml}$ of inflammatory exudates corresponding to the optical density values. Difference between the volumes of the right muscle before and the left muscle after the scheduled drug treatments can be expressed by the capacity of inflammatory exudates (in ml) [17].

\subsection{Statistical Analysis}

For performing the statistical calculation of the present study Graph pad Prism software version 6.01C, 1992-2012 was utilized. We have expressed all data mentioned in this study in terms of mean \pm SEM (standard error of the mean). We have conducted one way ANOVA (one-way analysis of variance) for analysis of statistical data along with treatment with Dunnett's multiple comparison test. We have set statistical significance (Pvalue $<0.05$ ) by following comparison made to the inflammatory control.

\section{RESULTS}

\subsection{Carrageenan Induced Inflammatory Muscle Hyperalgesia}

It has been noted that the production of inflammation of the muscle was developed after 24 hours of carrageenan injection in the gastrocnemius muscle and it was observed to occur continuously until chronic transformations one after 13 days. Figs. (1-3), showed details of a significant reduction in paw withdrawal latency to heat and mechanical stimuli respectively which was accompanied by the occurrence of inflammation. For the first two days, we observed spontaneous behavioural pain signs in animals such as guarding the injected paw and weight-bearing on the contra lateral side. We noted that there were no further signs of spontaneous pain signs, after 48 hours, except curling of the injected limb.

\subsection{Effects of $\boldsymbol{P}$. Fraternus Extract on Heat Hyperalgesia}

We have found that there was a remarkable reduction occurred for carrageenan induced heat stimuli when treated with $P$. fraternus extract. BPWL's (Basal paw withdrawal latencies) were found to be similar $(8.42 \pm 0.14$ seconds $)$ prior to carrageenan injection for all experimental groups and these were further reduced (to $2.87 \pm 0.12$ seconds) after duration of 2 weeks. It has been also observed that there was a rapid reduction in hyperalgesia occurred which was returned to normal within 1 hour when we gave The intraperitoneal $P$. fraternus extract administration. There was an observation of significant difference for PWL's to the heat stimuli for the groups injected with extracts and inflammatory control groups. The maximum response was achieved within a duration of 60 to 90 minutes after the administration of the extracts of $P$. fraternus. Fig. (2) shows the representation of the effects of extraction muscle hyperalgesia. We have achieved and recorded the maximum decrement in thermal response latency (TRL's) in DMSO vehicle treated animals. The results indicate that both the doses of $P$. fraternus extract have the ability to reduce thermal hyperalgesia significantly $\mathrm{P}<0.01$ vs. inflammatory control. P. fraternus extract significantly and dose dependently attenuated thermal hyperalgesia. Our current findings, demonstrated the similar efficacy of aceclofenac $(\mathrm{P}<0.01$ vs vehicle) with respect to inhibition of thermal hyperalgesia $(\mathrm{P}<0.01$ vs inflammatory control), when we did intraperitoneal administrations of extract. We have also 
achieved the attenuation of thermal hyperalgesia $(\mathrm{P}<0.05$ vs vehicle) with a lower dose of extract $(200 \mathrm{mg} / \mathrm{kg})$.

A Ipsilateral paw

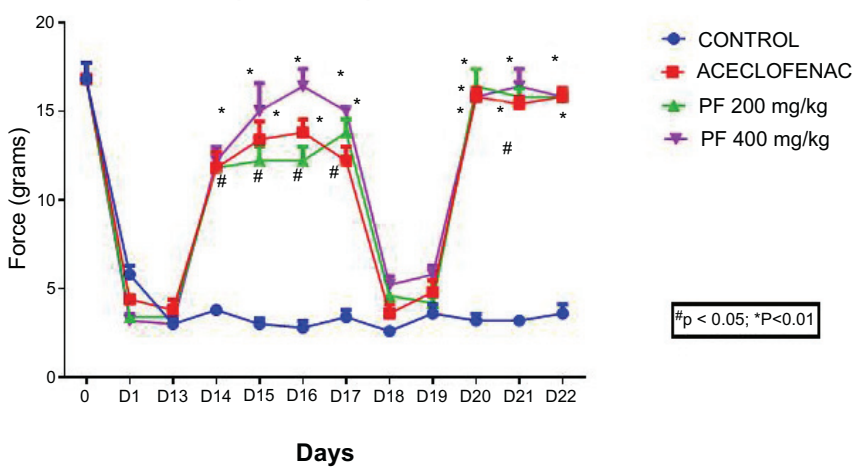

B Contralateral paw

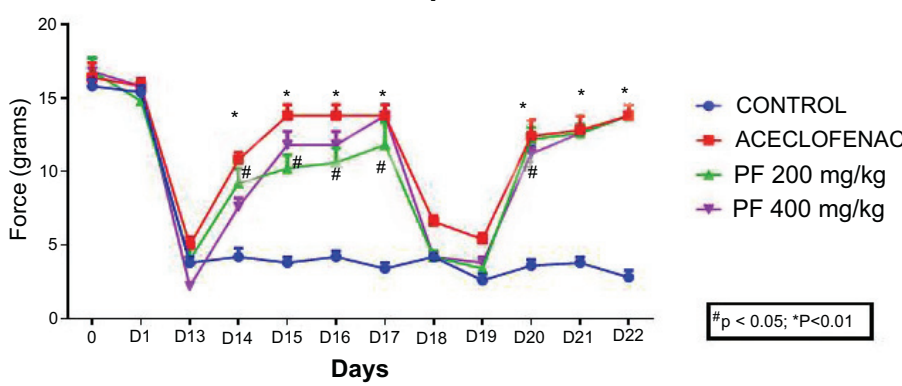

Fig. (1). Effects on Paw withdrawal thresholds to heat after injection of carrageenan into the muscle on the ipsilateral (A) and contra lateral side (B). The mean thermal withdrawal latency (in seconds) was measured for both the paws ipsilateral and contralateral in rats ( $\mathrm{n}=5$ for each group). Each point represents mean \pm standard error of mean of the paw withdrawal threshold (in seconds) to stimulation by heat.

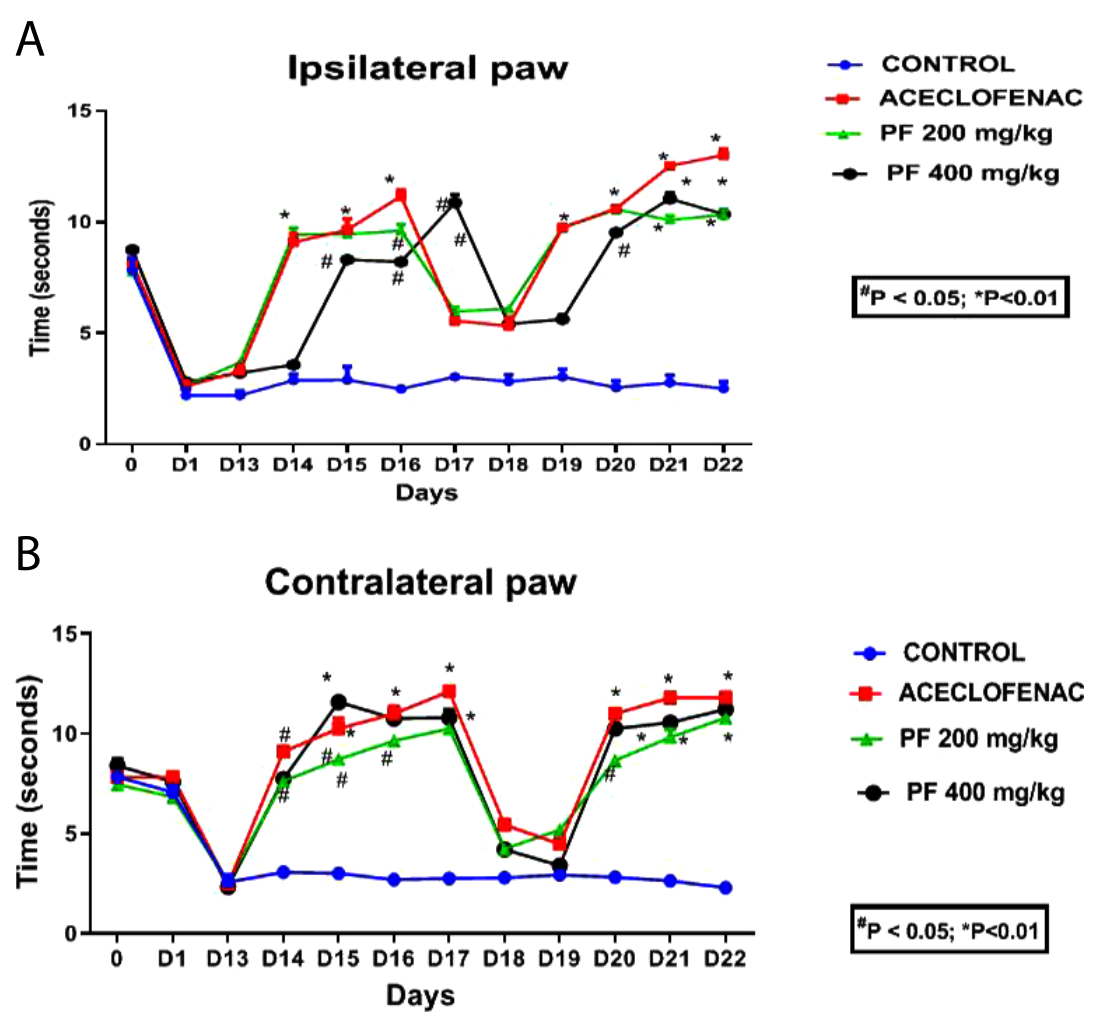

Fig. (2). Effects of Phyllanthus fraternus extract on paw withdrawal latency to heat in chronic inflammatory muscle hyperalgesia.

The mean thermal withdrawal latency (in seconds) was measured for both the paws ipsilateral and contralateral in rats ( $\mathrm{n}=5$ for each group). Each point represents mean \pm standard error of mean of the paw withdrawal threshold (in seconds) to stimulation by heat. Data were analyzed by one-way analysis of variance using Dunnett's multiple comparison test. $\mathrm{p}<0.05$ was considered significant as compared with the inflammatory control. 


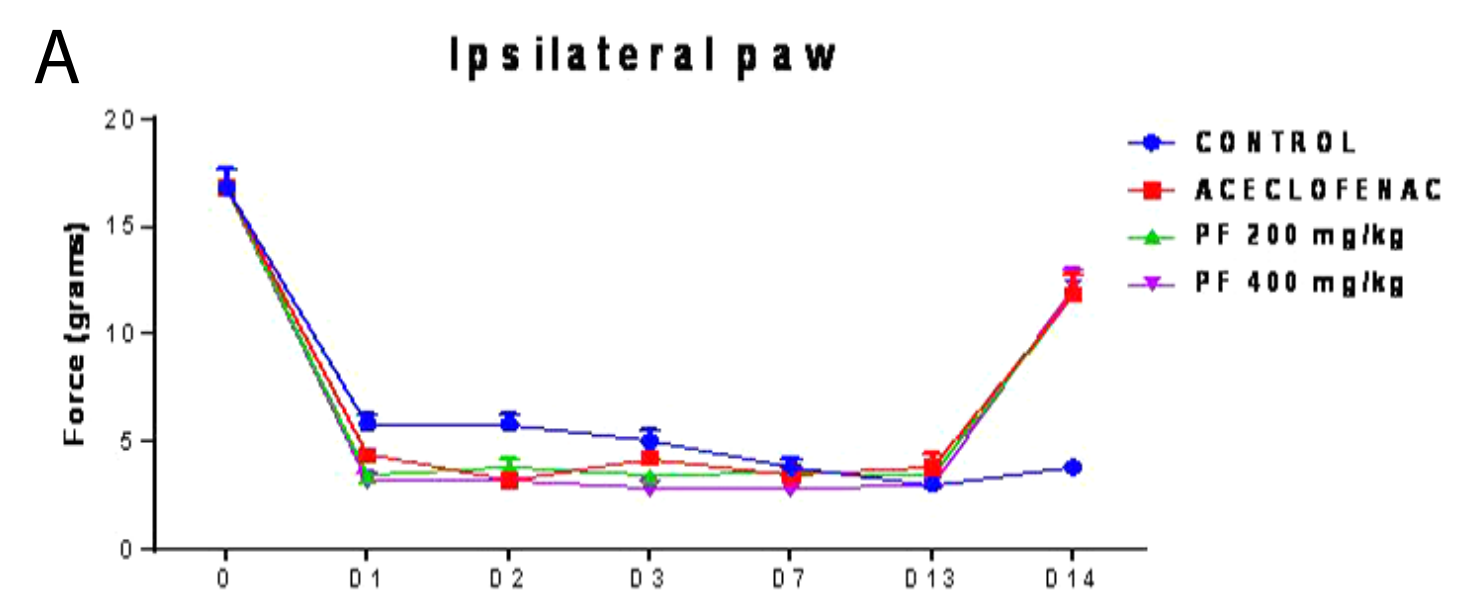

Days

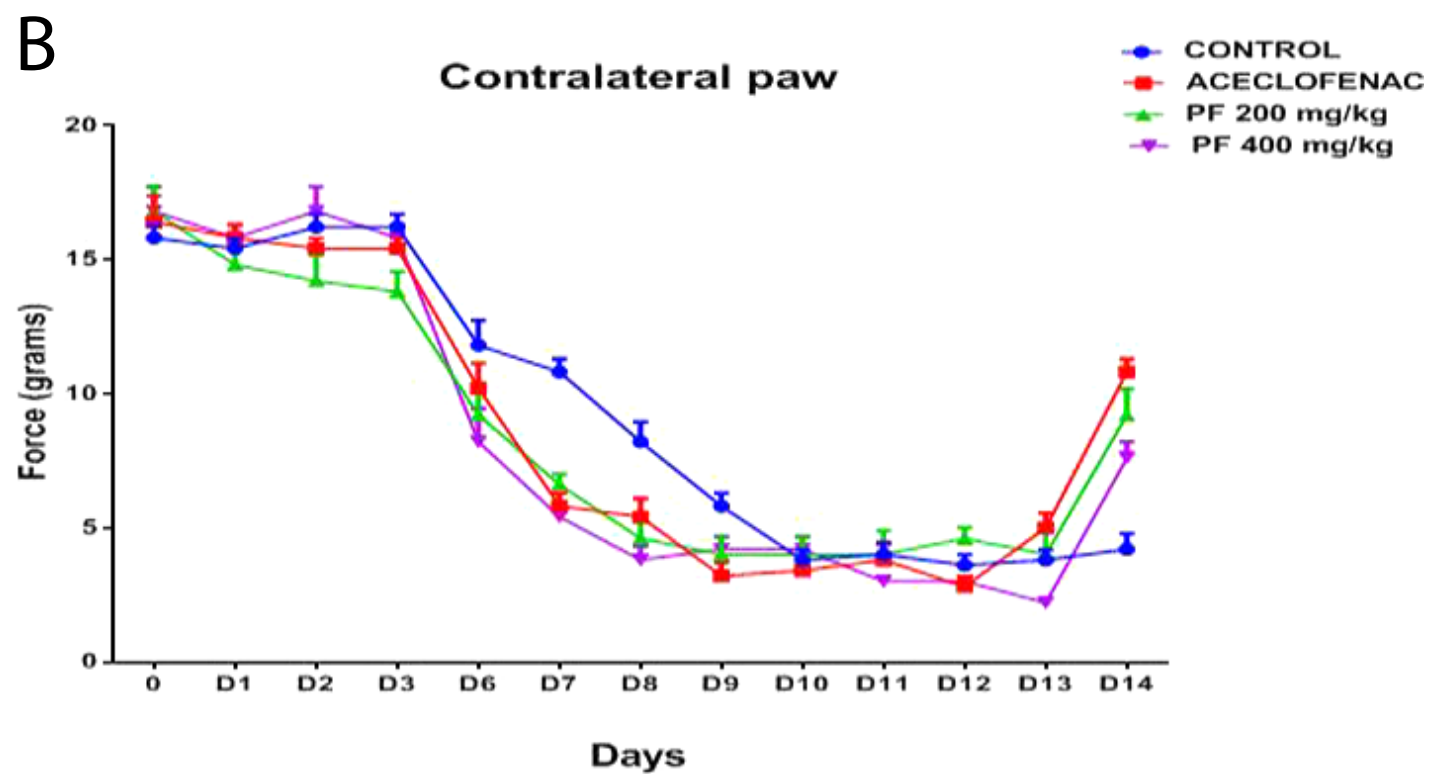

Fig. (3). Effects on Paw withdrawal thresholds to mechanical stimuli after injection of carrageenan into the muscle on the ipsilateral (A) and contra lateral side (B).

The mean thermal withdrawal latency (in seconds) was measured for both the paws ipsilateral and contralateral in rats ( $\mathrm{n}=5$ per group). Each point represents mean \pm standard error of mean of the paw withdrawalthreshold (in grams) to mechanical stimulation by von Frey filaments.

\subsection{Effect of P. Fraternus Extract on Mechanical Hyperalgesia}

Fig. (4) displays the effect of currently investigated extracts of $P$. fraternus on mechanical hyperalgesia in chronic inflammatory muscle hyperalgesia. We have obtained reduction in mechanical response threshold as seen in ipsilateral as well as contralateral paws for vehicle treated rodents. Mechanical hyperalgesia would significantly attenuate $(\mathrm{P}<0.05$ vs inflammatory control) with dosing of 200 and 400 $\mathrm{mg} / \mathrm{kg}$ of $P$. fraternus extracts. Our data also demonstrated the fact of similar efficacy of inhibition of mechanical hyperalgesia $(\mathrm{P}<0.01 v s$ inflammatory control) to Aceclofenac $(\mathrm{P}<0.01 v s$ vehicle). There was re-establishment of mechanical hypersensitivity occurred when we interrupted the $P$. fraternus extract treatment for two days (on the $18^{\text {th }}$ and $19^{\text {th }}$ day). On continuation of $P$. fraternus extract treatment on $20^{\text {th }}$ day, we started our study again. Significant reduction of mechanical hyperalgesia was observed again, excluding any probability tolerance development. 


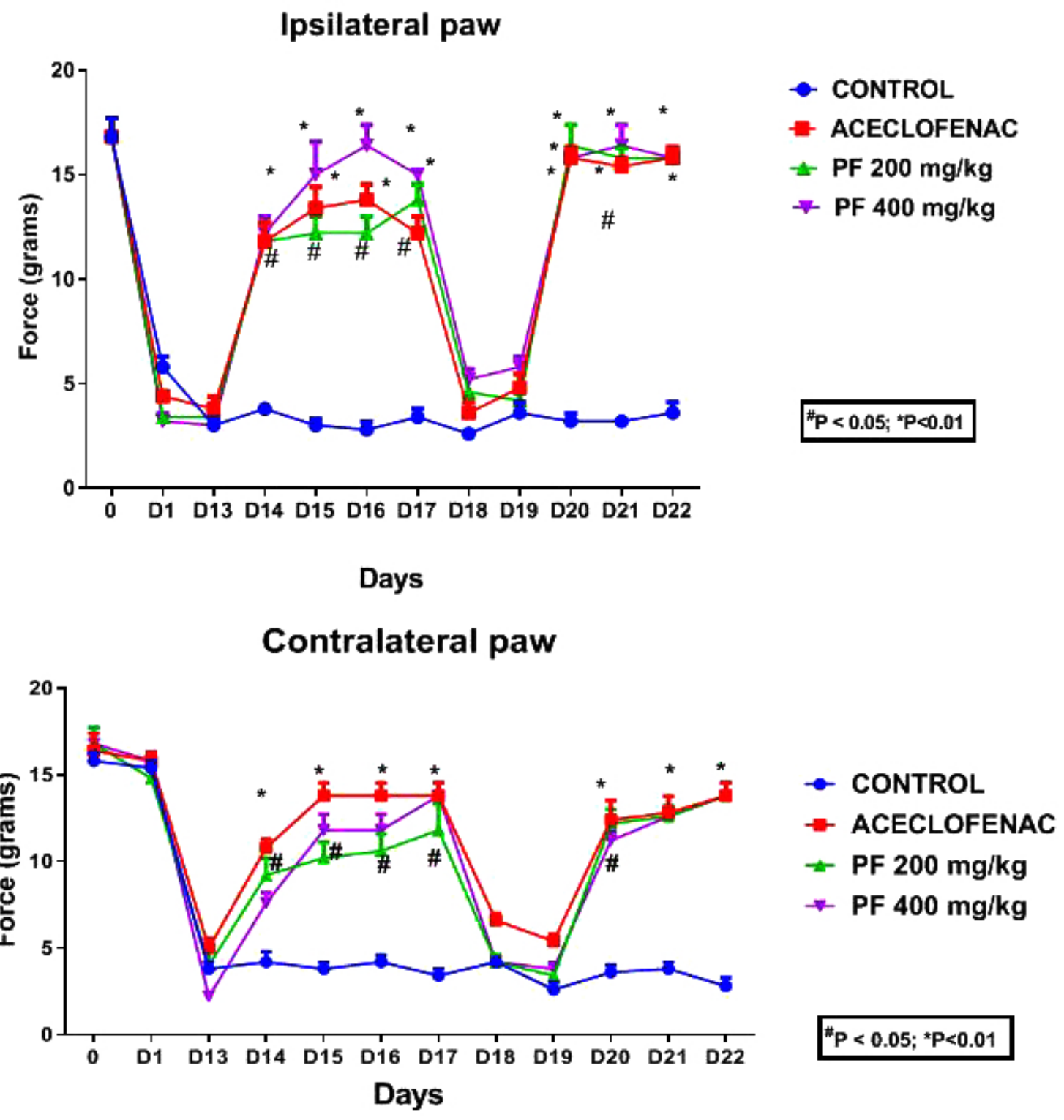

Fig. (4). Effects of Phyllanthus fraternus extract on paw withdrawal latency to mechanical stimuli in chronic inflammatory muscle hyperalgesia on the ipsilaterally (A) and contra lateral side (B).

The mean thermal withdrawal latency (in seconds) was measured for both the paws ipsilateral and contralateral in rats ( $\mathrm{n}=5$ per group). Each point represents mean \pm standard error of mean of the paw withdrawal threshold (in grams) to mechanical stimulation by von Frey filaments. Data were analyzed by one-way analysis of variance using Dunnett's multiple comparison test. $p<0.05$ was considered significant as compared with the inflammatory control.

\subsection{Effects of $\boldsymbol{P}$. fraternus Extract on Muscle Inflammation}

Development of distinct muscular inflammation in the control inflammatory group by carrageenan indicated the sign of inflammatory response as compared to the normal animals. We have noticed a decrease in circumference of muscle compared to the inflammatory control group, which was also an indication of decremental inhibition of muscle inflammation; when we loaded consecutive dosing of the extracts of $P$. fraternus, for details Fig. (5). 


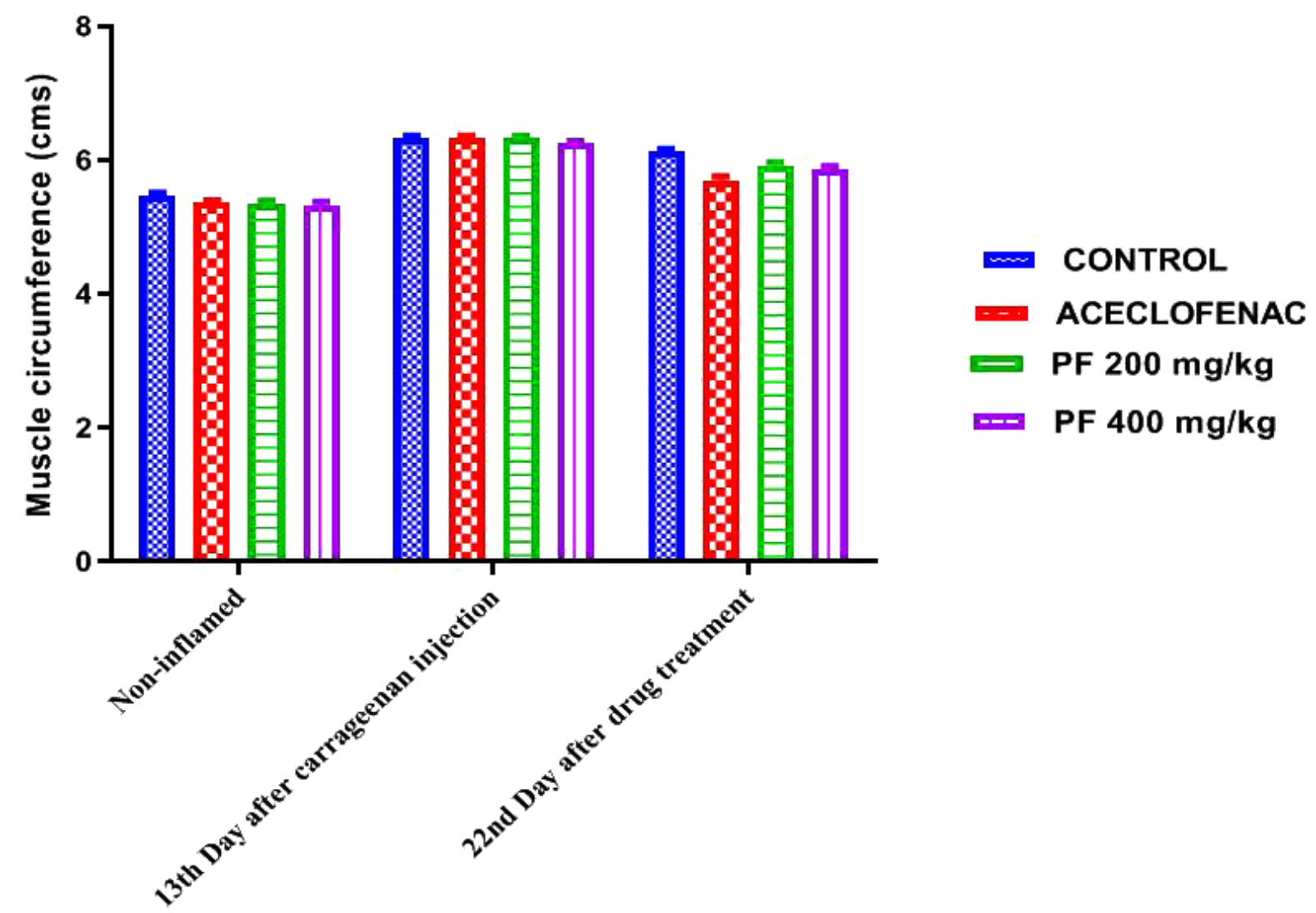

Fig. (5). Effect of Phyllanthus fraternus extract on muscle inflammation in chronic inflammatory hyperalgesia.

Effect of administration of Phyllanthus fraternus extract, Aceclofenac, or vehicle administered on muscle edema induced by carrageenan. Muscle diameter was measured only ipsilaterally. Each point represents the mean \pm standard error of mean of muscle thickness/diameter (in centimeters) before carrageenan injection (baseline) or at the times (13th and 22nd day) after intramuscular injection of Carrageenan.

\subsection{Effects of P. Fraternus Extract on Concentration of PGE2}

There was a significant decrease in levels of PGE2 in the edema exudates as compared with the control that was noticed when we allowed treatment with $P$. fraternus. We have also obtained better inhibitory potency of $P$. fraternus extracttreated groups as observed from (Fig. 6). When we increase the dose of $P$. fraternus extract, there was a gradual decrease in PGE2 concentration achieved. As the $0.186 \pm 0.26$ was obtained as basal PGE2concentration of normal control animals (without inflammation) when compared with $8.736 \pm$ 0.18 in the inflammatory control animals. Dosing of $400 \mathrm{mg} / \mathrm{kg}$ of $P$. fraternus extract parallel to the Aceclofenac group, caused significant attenuation of PGE2 concentration [17].

\subsection{Histopathological Studies}

Histopathological study of the inflamed tissues in the current study shows inhibition of inflammatory changes in $P$. fraternus extract treated animals. Inflammatory changes are parallel to the long lasting hyperalgesia observed in inflammatory control. Acute inflammation was severe in the hyperalgesic control which was accompanied by myonecrosis. Neutrophils were present in large numbers. The chronic inflammation was epimysial and perimysial. Few macrophages and scattered mast cells were also observed. Aceclofenac treated animals showed a decrease in the chronic macrophagic response as few macrophages were seen and without fibrinous exudates. The decrease in neutrophil count and absence of macrophages and mast cells was seen in the $P$. fraternus extract-treated rats as compared to hyperalgesic controls, for details Fig. (7). P. fraternus extract treatment shows inhibition of the macrophagic response to less extent.

\section{DISCUSSION}

\subsection{Antihyperalgesic and Pain Modulating Effects of $P$. fraternus Extract}

In the present study, we have checked the effects of extracts of $P$. fraternus on carrageenan induced mechanical as well as thermal hyperalgesia by doing systemic administrations in chronic model of inflammatory muscle hyperalgesia. In the previous study, which was demonstrated in Freund's complete adjuvant induced arthritis model and showed significant antiarthritic activity, which may be due to the contribution of antiinflammatory potential of standardized $P$. fraternus extract $[19$, 20].Various pharmacological potentials such as antioxidant, anti-inflammatory, and anti-apoptotic effects were reported by Kandhare et al. [21, 22] for phyllanthus extracts in acolitis model of inflammatory bowel disease; which was induced by acetic acid. Herein, we have demonstrated the potentials of $P$. fraternus extract on a previously reported and established 
muscle hyperalgesia in preclinical model. Due to series of central and peripheral changes happening particularly at the site of injury; which obviously believed to be maintained by spinal or supraspinal neuronal mechanisms was responsible for observations of chronic thermal and mechanical hyperalgesia in the current model [21 - 24]. Herein, we observed that there was a reversion of chronic hyperalgesia when there was the administration of $P$. fraternus extract. It has also been concluded from our histopathological studies that no observations occurred for contra lateral signs of inflammation during our study. The probable contra lateral spread of hyperalgesia may be supported by the neuronal role (spinal or supraspinal). Herein from our current findings, we could say that there may be alleviation of pain threshold of muscle mediated inflammatory hyperalgesia by extracts of $P$. fraternus and there will be no contribution to inflammatory pain, although there will establishments of ongoing inflammation. It has also be noted that phyllanthus extracts maintain its efficacy although we repeated intraperitoneal administrations of same and the anti-hyperalgesic effects were not susceptible to tolerance. We know the importance of that spinal COX-2 in the maintenance of carrageenan induced muscle hyperalgesia [25]. It has been observed that there were occurrences of allodynia and hyperalgesia after inflammation, which was an0 indication of fact of increase in levels of PGE2 in the inflamed tissue. These attributes may be the indication of involvement of the spinal cord for induction and activation of COX-2. In almost all inflammatory pain conditions, there will be an active involvement of COX-2 enzyme as a source of PGE2, and inhibition to this enzyme ultimately leads to antihyperalgesic activity as proved and observed for 2 -selective inhibitory drugs. If one wants to modulate or treat chronic inflammatory pain [17], there should be inhibition of PGE2 synthesis (mainly of COX-2 inhibitions) as suggested by Pulichino et al. It has been reported in literature for inhibition of endotoxin induced COX-2 and cytokine production when treated with extract of Phyllanthus species in in vitro as well as in in vivo models [20]. We have observed signifiacnt reduction of PGE2 levels in $P$. fraternus extract treated edema exudates of the rats and groups treated with standard aceclofenac and it was comparable with the chronic inflammatory control. We have also noticed improvements in inflammatory changes as supported by our histopathological studies, which was thought to be paralleled to the long-lasting thermal and mechanical hyperalgesia.

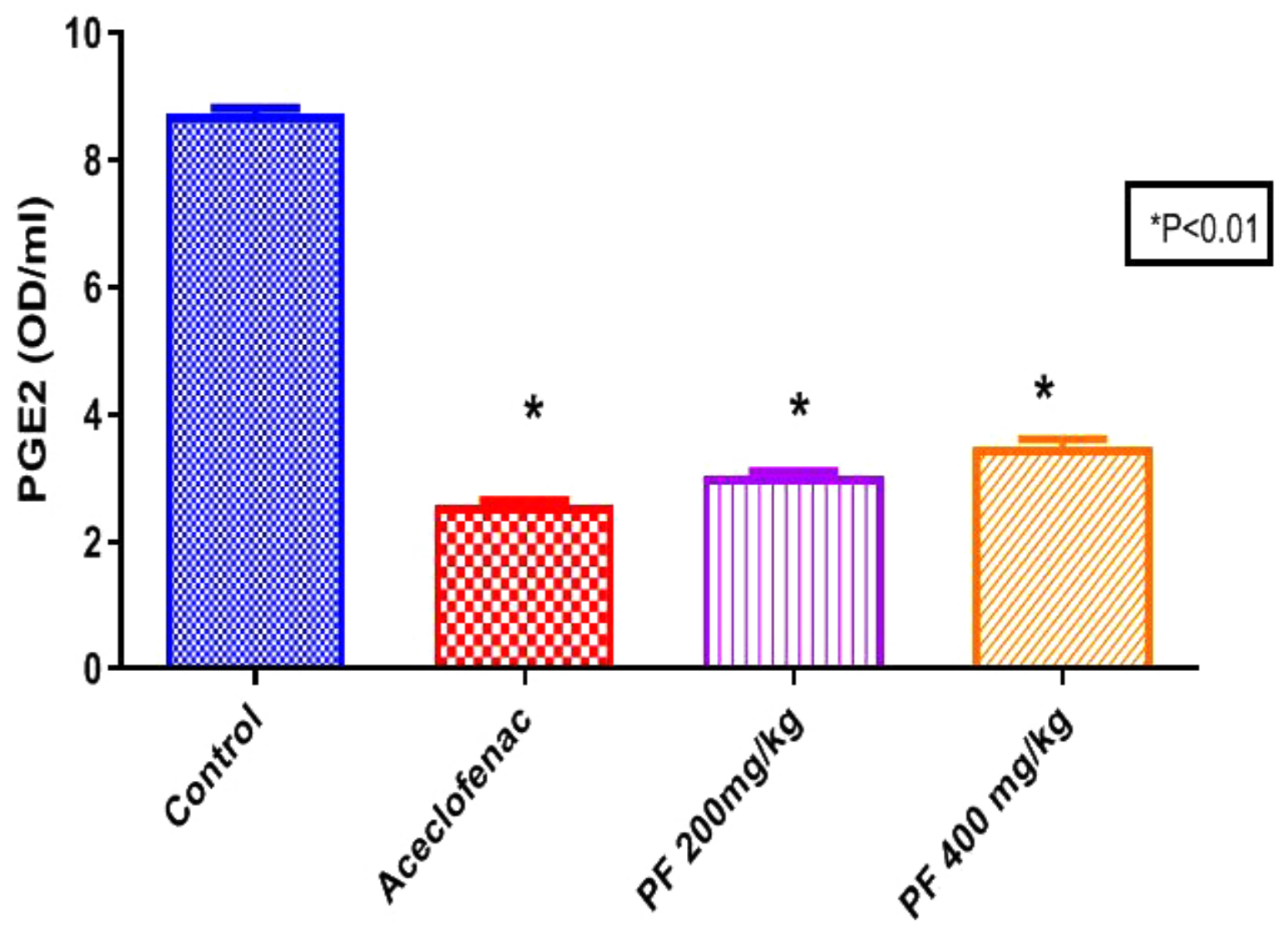

Fig. (6). Effects of Phyllanthus fraternus extract on PGE2 concentration in muscle exudates induced by Carrageenan in rats.

Each bar represents the mean \pm standard error of mean of the PGE2 concentration (in optical density/ml). Data were analyzed by one-way analysis of variance using Dunnett's multiple comparison test. $\mathrm{p}<0.05$ was considered significant in comparison with inflammatory control. 


\subsection{Lignans and Tannins From P. Fraternus and Their Role in Modulation of Pain}

The preliminary phytochemical study showed that the $P$. fraternus extract was rich in lignans as well as tannins. The phytochemical finger print analysis of the standardized extract of $P$. fraternus extract clearly indicates that the observed antihyperalgesic activity in the studied extract may be due to presence of lignans and tannins. From the HPTLC chromatograms, we can interpret that the $P$. fraternus extract contained considerable amount of lignans(phyllanthin and hypophyllanthin) and tannins (corilagin). HPTLC analyses of $P$. fraternus extract revealed significant peaks distinct for phyllanthin, hypophyllanthin and corilagin, which are depicted in Fig. (8). Therefore we suggest that the presence of lignans and tannin compounds might be the reason for their bioactive role against chronic pain. As ligans are major phytoconstituents of phyllanthus species, they are reported for a number of biological activities such as immunomodulatory activity, antiinflammatory, antioxidant, anti-arthritic and analgesic [24 28]. Kassuya et al. reported the purified lignans isolated from extracts of phyllanthus such as phyltetralin, nirtetralin and niranthin for their anti-inflammatory effects. Furthermore, there are several reports for mainly niranthin, which was found to have interference with PAF induced inflammatory response [27 - 33]. Corilagin present in extracts of phyllanthus also reported for anti-hyperalgesic activity [25].
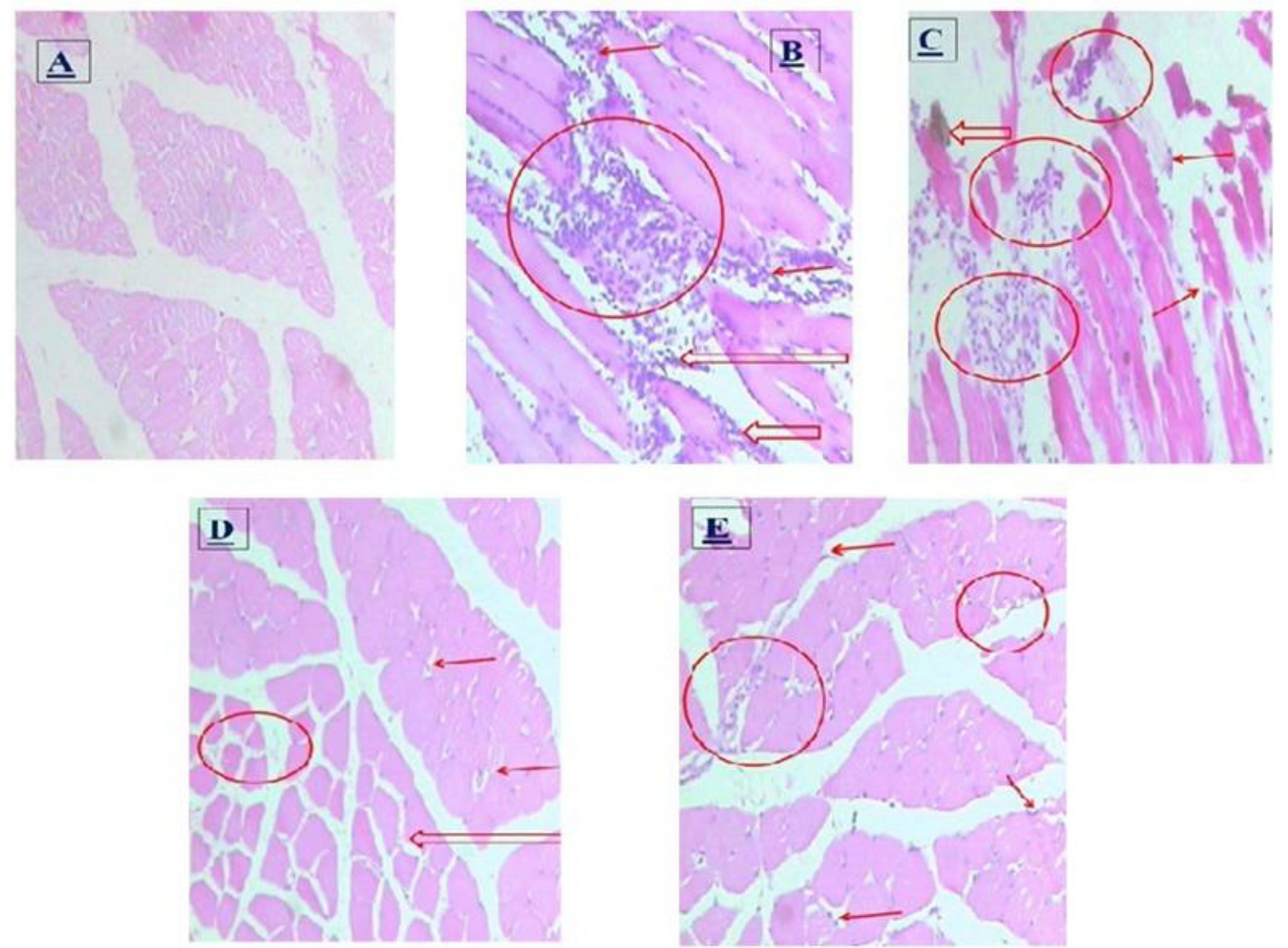

Fig. (7). Photomicrographs of muscle pathology.

Histopathological changes in gastrocnemius muscle in normal, chronic inflammatory control, Aceclofenac and P. fraternus extract (only $400 \mathrm{mg} / \mathrm{kg}$ ) treated groups are shown. Circles show foci of muscle necrosis and arrows show group of inflammatory cell infiltrates and macrophages in chronic hyperalgesic controls and subsequent drug treated groups. Micro photographs were taken at a magnification of 40 X 10 x. (․) Histological slide of gastrocnemius muscle of normal healthy rat. ( $\underline{\mathbf{B}})$ Acute inflammatory response showing hemorrhage, edema and inflammatory cell infiltrates mostly neutrophils are seen signifying acute inflammatory response accompanied by myonecrosis. ( $\underline{\mathbf{C}})$ Chronic inflammatory response showing primarily the macrophages and scattered mast cells. (D) Aceclofenac treated rats $(\underline{\mathbf{E}}) P$. fraternus extract $(400 \mathrm{mg} / \mathrm{kg})$ treated rats. 

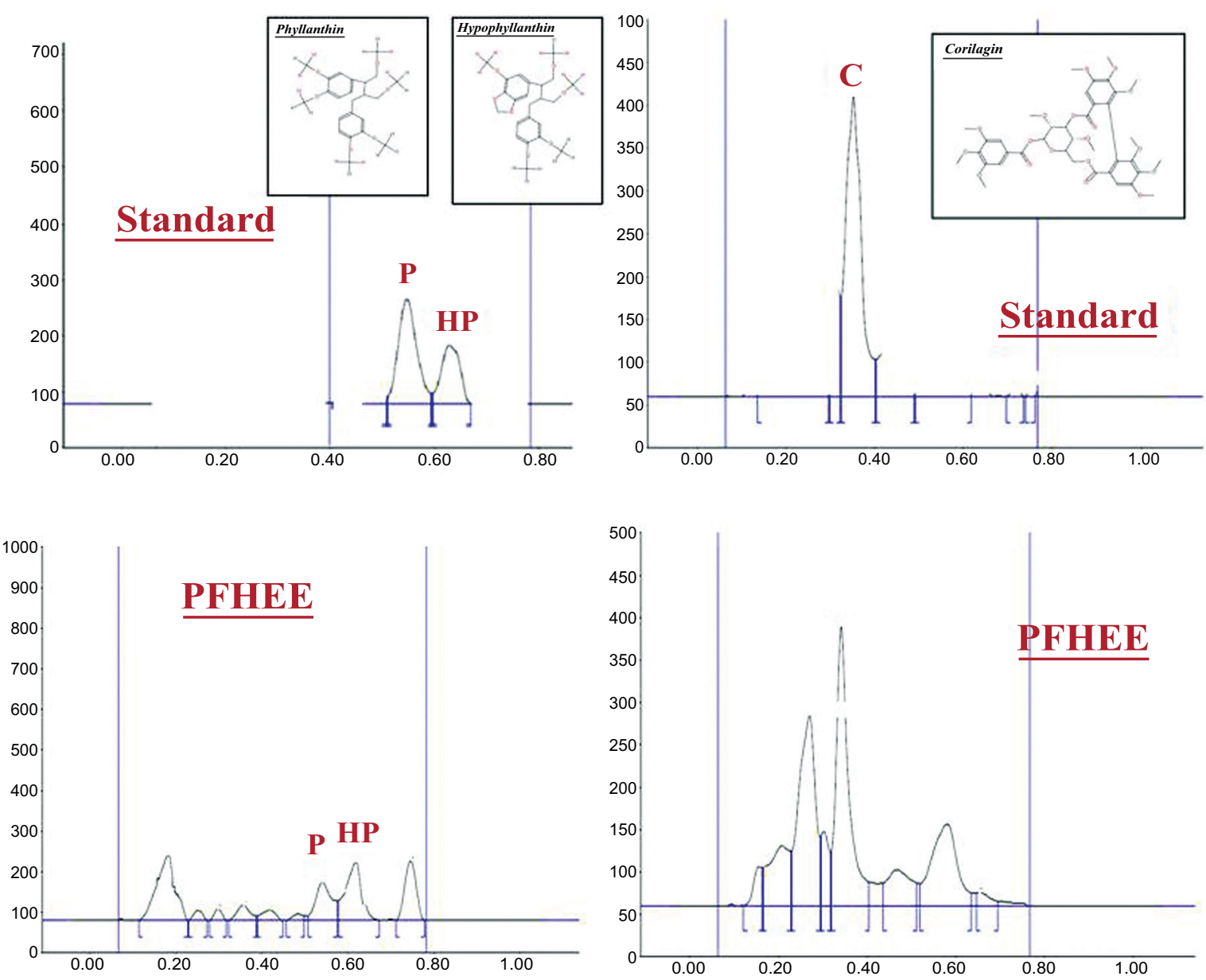

Fig. (8). HPTLC finger print of Phyllanthus fraternus extract.

For detection of Lignans mobile phase used was chloroform: methanol: water (7:3:0.4, v/v). For detection of Tannins mobile phase used was toluene: Ethyl acetate: formic acid (6:4:0.3, v/v).

$P$. amarus extract significantly inhibited the production of pro-inflammatory mediators (TNF- $\alpha, \mathrm{IL}-1 \beta, \mathrm{PGE}_{2}$ ) and COX-2 protein expression in LPS-induced U937 human macrophages. The quantitative amounts of lignans, phyllanthin, hypophyllahtin and niranthin, and polyphenols, gallic acid, geraniin, corilagin, and ellagic acid in the Phyllaanthus extract were attributed for anti-inflammatory activity [33]. Hemavathy et al. reviewed focusing on the lignans (phyllanthin, hypophyllanthin, and niranthin), tannins (corilagin, geraniin, ellagic acid, gallic acid) of various anti-inflammatory activities of Phyllanthus exert via perturbation of the NF- $\mathrm{BB}$, MAPKs, PI3K/Akt, and Wnt signaling networks [34]. Jantan et al. [35] reviewed the significance of Phyllanthus species and their bioactive metabolites particularly corilagin, phyllanthin, hypophyllanthin and niranthin in the modulation of both innate and adaptive immune systems through various mechanisms and their possible therapeutic benefits for treatment of immunerelated diseases [34]. Hemavathy et al. observed phyllanthin may exert their suppressive effects on inflammatory process by mediating the release of inflammatory signaling molecules via the NF-KB, MAPKs, and PI3K-Akt signal transducing pathways [36]. It is demonstrated that Hypophyllanthin and
Niranthin downregulated COX-2, TNF- $\alpha$, and IL-1 $1 \beta$ gene expressions in U937 macrophages by interfering with the activation of NF- $\kappa \mathrm{B}$, MAPKs, and Akt [36]. Our previous studies on $[10,12]$ phyllanthus species also support the chronic pain modulating potential of these species as like our current findings. Molecular modelling studies conducted for docking of various phytoconstituents from phyllanthus species also suggested the docking potentials of these constituents on various targets proteins involved in inflammatory hyperalgesia. Our current finding confirmed the pain modulating potential of Phyllanthus fraternus species as it is rich in the lignans and tannins. In order to develop effective drugs for chronic pain treatment, further experimental evaluation is essential for phytoconstituents like phyllanthin, hypophyllanthin and corilagin. Nowadays, we are more focusing on synthesis, catalysis, molecular modelling studies and implications to various biological activities [37 - 57].

\section{CONCLUSION}

In our current study, we have demonstrated the good antihyperalgesic and anti-inflammatory potentials of extracts of fraternus in a chronic pain model. These activities might be 
contributed because of the presence of phytoconstituents like hypophyllanthin, phyllanthin, and corilagin. These phytoconstituents may find usefulness in treatments of chronic inflammatory muscle pain.

\section{LIST OF ABBREVIATIONS}

$\begin{array}{lll}\text { PGE2 } & = & \text { Prostaglandin E-2 } \\ \text { DMSO } & = & \text { Dimethyl sulfoxide } \\ \text { COX } & = & \text { Cyclooxygenase } \\ \text { P. Fraternus } & = & \text { Phyllanthus fraternus }\end{array}$

\section{ETHICS APPROVAL AND CONSENT TO PARTICIPATE}

All necessary approvals for the current study were taken from the Animal Ethics Committee of Govt. College of Pharmacy, Karad, India (GCOPK) [Reference: CPCSEA / IAEC- 2012-MAR/01].

\section{HUMAN AND ANIMAL RIGHTS}

No humans were used in this study. All necessary experiments were carried as per the guidelines suggested by CPCSEA for the care of laboratory animals and corresponding the ethical guidelines for animals as specified $[15,16]$.

\section{RESEARCH INVOLVING PLANTS}

The plant species was identified and authenticated by Botanical survey of India, Pune [Reference No. BSI/WC/Tech./2012/644]. We followed the guidelines suggested by Botanical survey of India.

\section{CONSENT FOR PUBLICATION}

Not applicable.

\section{AVAILABILITY OF DATA AND MATERIALS}

The data that support the findings of this study are available from the corresponding authors [A.R.C] and [S.N.M] upon reasonable request.

\section{FUNDING}

The authors are thankful to the University Grants Commission (UGC) for providing grant [Grant reference no. F.16-1917(SC)/2010 (SA-III)] to A.R.C.

\section{CONFLICT OF INTEREST}

The authors declare no conflict of interest, financial or otherwise.

\section{ACKNOWLEDGEMENTS}

All authors acknowledge the help and support provided by Rajarambapu College of Pharmacy, Kasegaon, India.

\section{REFERENCES}

[1] Chopade AR, Mulla WA. Novel strategies for the treatment of inflammatory hyperalgesia. Eur J Clin Pharmacol 2010; 66(5): 429-44. [http://dx.doi.org/10.1007/s00228-010-0784-7] [PMID: 20155257]

[2] Chopade AR, Naikwade NS, Burade KB. Hyperalgesic models: To study chronic pain effectively. Electr J Pharmacol 2008; 1: 67-73.
[3] Khanna D, Sethi G, Ahn KS, et al. Natural products as a gold mine for arthritis treatment. Curr Opin Pharmacol 2007; 7(3): 344-51. [http://dx.doi.org/10.1016/j.coph.2007.03.002] [PMID: 17475558]

[4] Harvey AL. Natural products in drug discovery. Drug Discov Today 2008; 13(19-20): 894-901.

[http://dx.doi.org/10.1016/j.drudis.2008.07.004] [PMID: 18691670]

[5] Calixto JB, Santos AR, Cechinel Filho V, Yunes RA. A review of the plants of the genus Phyllanthus: their chemistry, pharmacology, and therapeutic potential. Med Res Rev 1998; 18(4): 225-58.

[http://dx.doi.org/10.1002/(SICI)1098-1128(199807)18:4<225::AIDMED2>3.0.CO;2-X] [PMID: 9664291]

[6] Bagalkotkar G, Sagineedu SR, Saad MS, Stanslas J. Phytochemicals from Phyllanthus niruri Linn. and their pharmacological properties: A review. J Pharm Pharmacol 2006; 58(12): 1559-70.

[http://dx.doi.org/10.1211/jpp.58.12.0001] [PMID: 17331318]

[7] Joseph B, Raj SJ. An overview: Pharmacognostic properties of Phyllanthus amarus Linn. Int J Pharmacol 2011; 7(1): 40-5.

[http://dx.doi.org/10.3923/ijp.2011.40.45]

[8] Patel JR, Tripathi P, Sharma V, Chauhan NS, Dixit VK. Phyllanthus amarus: Ethnomedicinal uses, phytochemistry and pharmacology: A review. J Ethnopharmacol 2011; 138(2): 286-313.

[http://dx.doi.org/10.1016/j.jep.2011.09.040] [PMID: 21982793]

[9] Sarin B, Verma N, Martín JP, Mohanty A. An overview of important ethnomedicinal herbs of Phyllanthus species: Present status and future prospects. Sci World J 2014; 839172: 12.

[10] Chopade AR, Sayyad FJ. Antifibromyalgic activity of standardized extracts of Phyllanthus amarus and Phyllanthus fraternus in acidic saline induced chronic muscle pain. Biomed Aging Pathol 2014; 4: 123-30.

[http://dx.doi.org/10.1016/j.biomag.2014.01.005]

[11] Chopade AR, Sayyad FJ, Pore YV. Molecular docking studies of phytocompounds from the phyllanthus species as potential chronic pain modulators. Sci Pharm 2014; 83(2): 243-67.

[http://dx.doi.org/10.3797/scipharm.1408-10] [PMID: 26839814]

[12] Chopade AR, Sayyad FJ, Naikwade NS. Pharmacological characterization of carrageenan induced heat muscle hyperalgesia in rats using non-selective, preferential and selective COX-2 inhibitors. Pharmacol Rep 2014; 66(3): 353-62.

[http://dx.doi.org/10.1016/j.pharep.2013.12.011] [PMID: 24905509]

[13] Chopade AR, Sayyad FJ. Antinociceptive effect of Phyllanthus fraternus extract in complete Freund's adjuvant induced chronic pain in mice. Biomed Aging Pathol 2013; 3(4): 235-40. [http://dx.doi.org/10.1016/j.biomag.2013.09.001]

[14] Radhakrishnan R, Moore SA, Sluka KA. Unilateral carrageenan injection into muscle or joint induces chronic bilateral hyperalgesia in rats. Pain 2003; 104(3): 567-77.

[http://dx.doi.org/10.1016/S0304-3959(03)00114-3] [PMID: 12927629]

[15] Radhakrishnan R, Sluka KA. Acetazolamide, a carbonic anhydrase inhibitor, reverses inflammation-induced thermal hyperalgesia in rats. J Pharmacol Exp Ther 2005; 313(2): 921-7. [http://dx.doi.org/10.1124/jpet.104.082776] [PMID: 15743922]

[16] Zimmermann M. Ethical guidelines for investigations of experimental pain in conscious animals. Pain 1983; 16(2): 109-10.

[http://dx.doi.org/10.1016/0304-3959(83)90201-4] [PMID: 6877845]

[17] Chopade AR, Sayyad FJ. Pain modulation by lignans (phyllanthin and hypophyllanthin) and tannin (corilagin) rich extracts of Phyllanthus amarus in carrageenan induced thermal and mechanical chronic muscle hyperalgesia. Phytother Res 2015; 29(8): 1202-10. [http://dx.doi.org/10.1002/ptr.5366] [PMID: 25974715]

[18] Matsuda R, Tanihata S. [Suppressive effect of sialic acid on the prostaglandin E2-mediated edema in carrageenin-induced inflammation of rat hind paws]. Nippon Yakurigaku Zasshi 1992; 99(5): 363-72.

[http://dx.doi.org/10.1254/fpj.99.363] [PMID: 1592319]

[19] Winter CA, Risley EA, Nuss GW. Carrageenin-induced edema in hind paw of the rat as an assay for antiinflammatory drugs. Proc Soc Biol Med 1962; 1: 544-7.

[http://dx.doi.org/10.3181/00379727-111-27849]

[20] Pulichino AM, Rowland S, Wu T, et al. Prostacyclin antagonism reduces pain and inflammation in rodent models of hyperalgesia and chronic arthritis. J Pharmacol Exp Ther 2006; 319(3): 1043-50. [http://dx.doi.org/10.1124/jpet.106.110387] [PMID: 16973887]

[21] Jain NK, Kulkarni SK, Singh A. Role of cysteinyl leukotrienes in nociceptive and inflammatory conditions in experimental animals. Eur J Pharmacol 2001; 423(1): 85-92.

[http://dx.doi.org/10.1016/S0014-2999(01)01083-4] [PMID: 
11438310]

[22] Kandhare AD, Ghosh P, Ghule AE, Zambare GN, Bodhankar SL. Protective effect of Phyllanthus amarus by modulation of endogenous biomarkers and DNA damage in acetic acid induced ulcerative colitis: Role of phyllanthin and hypophyllanthin. Apollo Med 2013; 10(1): 87-97.

[http://dx.doi.org/10.1016/j.apme.2013.01.006]

[23] Araldi D, Ferrari LF, Lotufo CM, et al. Peripheral inflammatory hyperalgesia depends on the COX increase in the dorsal root ganglion. Proc Natl Acad Sci USA 2013; 110(9): 3603-8

[http://dx.doi.org/10.1073/pnas.1220668110] [PMID: 23401543]

[24] Ossipov MH, Dussor GO, Porreca F. Central modulation of pain. J Clin Invest 2010; 120(11): 3779-87. [http://dx.doi.org/10.1172/JCI43766] [PMID: 21041960]

[25] Kiemer AK, Hartung T, Huber C, Vollmar AM. Phyllanthus amarus has anti-inflammatory potential by inhibition of iNOS, COX-2, and cytokines via the NF-kappaB pathway. J Hepatol 2003; 38(3): 289-97. [http://dx.doi.org/10.1016/S0168-8278(02)00417-8] [PMID: 12586294]

[26] Ofuegbe SO, Adedapo AA, Adeyemi AA. Anti-inflammatory and analgesic activities of the methanol leaf extract of Phyllanthus amarus in some laboratory animals. J Basic Clin Physiol Pharmacol 2014; 25(2): $175-80$

[http://dx.doi.org/10.1515/jbcpp-2013-0084] [PMID: 23893681]

[27] Moreira J, Klein-Júnior LC, Cechinel Filho V, de Campos Buzzi F. Anti-hyperalgesic activity of corilagin, a tannin isolated from Phyllanthus niruri L. (Euphorbiaceae). J Ethnopharmacol 2013; 146(1): $318-23$.

[http://dx.doi.org/10.1016/j.jep.2012.12.052] [PMID: 23333746]

[28] Raphael KR, Kuttan R. Inhibition of experimental gastric lesion and inflammation by Phyllanthus amarus extract. J Ethnopharmacol 2003; 87(2-3): 193-7.

[http://dx.doi.org/10.1016/S0378-8741(03)00120-X] [PMID: 12860307]

[29] Kassuya CA, Silvestre AA, Rehder VLG, Calixto JB. Anti-allodynic and anti-oedematogenic properties of the extract and lignans from Phyllanthus amarus in models of persistent inflammatory and neuropathic pain. Eur J Pharmacol 2003; 478(2-3): 145-53. [http://dx.doi.org/10.1016/j.ejphar.2003.08.079] [PMID: 14575799]

[30] Kassuya CA, Silvestre A, Menezes-de-Lima O Jr, Marotta DM, Rehder VLG, Calixto JB. Antiinflammatory and antiallodynic actions of the lignan niranthin isolated from Phyllanthus amarus. Evidence for interaction with platelet activating factor receptor. Eur J Pharmacol 2006; 546(1-3): 182-8

[http://dx.doi.org/10.1016/j.ejphar.2006.07.025] [PMID: 16925995]

[31] Mali SM, Sinnathambi A, Kapase CU, Bodhankar SL, Mahadik KR. Anti-arthritic activity of standardised extract of Phyllanthus amarus in Freund's complete adjuvant induced arthritis. Biomed Aging Pathol 2011; 1: 185-90.

[http://dx.doi.org/10.1016/j.biomag.2011.09.004]

[32] Dirig DM, Isakson PC, Yaksh TL. Effect of COX-1 and COX-2 inhibition on induction and maintenance of carrageenan-evoked thermal hyperalgesia in rats. J Pharmacol Exp Ther 1998; 285(3): 1031-8. [PMID: 9618405]

[33] Wu W, Li Y, Jiao Z, Zhang L, Wang X, Qin R. Phyllanthin and hypophyllanthin from Phyllanthus amarus ameliorates immuneinflammatory response in ovalbumin-induced asthma: role of IgE, Nrf2, iNOs, TNF- $\alpha$, and IL's. Immunopharmacol Immunotoxicol 2019; 41(1): 55-67.

[http://dx.doi.org/10.1080/08923973.2018.1545788] [PMID: 30541359]

[34] Harikrishnan H, Jantan I, Alagan A, Haque MA. Modulation of cell signaling pathways by Phyllanthus amarus and its major constituents: potential role in the prevention and treatment of inflammation and cancer. Inflammopharmacol 2019; pp. 1-18.

[35] Ibrahim J. Md, Areeful H.; Menaga, I.; Laiba, A. . An insight into the modulatory effects and mechanisms of action of phyllanthus species and their bioactive metabolites on the immune system. Front Pharmacol 2019; 7-, 10, 878 .

[36] Harikrishnan H, Jantan I, Haque MA, Kumolosasi E. Antiinflammatory effects of Phyllanthus amarus Schum. \& Thonn. through inhibition of NF- $\kappa \mathrm{B}$, MAPK, and PI3K-Akt signaling pathways in LPS-induced human macrophages. BMC Complement Altern Med 2018; 18(1): 224.

[http://dx.doi.org/10.1186/s12906-018-2289-3] [PMID: 30045725]

[37] Desale V, Thorat BR, Yamgar RS, Mali SN. Synthesis, admetSAR predictions, DPPH radical scavenging activity and potent antimycobacterial studies of hydrazones of substituted 4(anilinomethyl)benzohydrazides (Part 2) Curr Comput Aided Drug Des. Accepted Manuscript 2020.

[38] Mali S, Pratap A. Targeting infectious Coronavirus Disease 2019 (COVID-19) with Artificial Intelligence (AI) applications: Evidence based opinion. Infect Diso Drug Targets 2020.

[39] Chopade A, Dias R, Mali S. An In-Silico and in vivo approaches:An Insight Into the anxiolytic Effects of Lignans (Phyllanthin and Hypophyllanthin) and Tannin (Corilagin) Rich Extracts of Phyllanthus amarus. Comb Chem High Through Screen 2020.

[40] Mali SN, Thorat BR, Chopade AR. A viewpoint on angiotensinconverting enzyme 2, anti-hypertensives and coronavirus disease 2019 (COVID-19). Infect Disord Drug Targets 2020. [http://dx.doi.org/10.2174/1871526520666200511005546] [PMID: 32389117]

[41] Thorat BR, Rani D, Mali SN, Yamgar RS. Synthesis, In-silico and Invitro analysis of hydrazones as potential antituberculosis agents. Curr Comput Aided Drug Des 2020. [Epub ahead of print]

[http://dx.doi.org/10.2174/1573409916666200302120942]

[42] Thorat BR, Rani D, Yamgar RS, Mali SN. Synthesis, Spectroscopic, In-vitro and Computational analysis of hydrazones as potential antituberculosis agents: (Part-I). Comb Chem High Throughput Screen 2020; 23(5): 392-401. Epub ahead of print

[http://dx.doi.org/10.2174/1386207323999200325125858] [PMID: 32209038]

[43] Jadhav BS, Yamgar RS, Kenny RS, Mali SN, Chaudhari HK, Mandewale MC. Synthesis and In-silico identification of new bioactive 1,3,4-oxadiazole tagged 2,3-dihydroimidazo[1,2-a]pyridine derivatives. Curr Bioact Compd 2020.

[44] Thorat BR, Mali SN, Dalvi B. Green Synthesis of Substituted dihydropyrimidin-2(1H)-one by using Zinc Chloride /acetic acid Catalytic System. Current Chinese Chemistry 2020. [http://dx.doi.org/10.2174/2665997201999200512110147]

[45] Desale VJ, Mali SN, Chaudhari HK, Mali MC, Thorat BR, Yamgar RS. Synthesis and Anti-mycobacterium Study of halo-substituted 2aryloxyacetohydrazones. Curr Comput Aided Drug Des 2019; 15 : 1. [http://dx.doi.org/10.2174/1573409915666191018120611] [PMID: 31648645]

[46] Mali SN, Chaudhari HK. Computational studies on imidazo [1,2-a] pyridine-3-carboxamide analogues as antimycobacterial agents: Common pharmacophore generation, atom-based 3d-qsar, molecular dynamics simulation, qikprop, molecular docking and prime mmgbsa approaches. Open Pharm Sci J 2018; 5(1): 12-23.

[http://dx.doi.org/10.2174/1874844901805010012]

[47] Mali SN, Chaudhari HK. Molecular modelling studies on adamantanebased Ebola virus GP-1 inhibitors using docking, pharmacophore and 3D-QSAR. SAR QSAR Environ Res 2019; 30(3): 161-80. [http://dx.doi.org/10.1080/1062936X.2019.1573377]

[PMID: 30786763]

[48] Mali SN, Sawant S, Chaudhari HK, Mandewale MC. In silico appraisal, Synthesis, Antibacterial screening and DNA cleavage for 1,2,5-thiadiazole derivative. Curr Comput Aided Drug Des 2019; 15(5): 445-55.

[http://dx.doi.org/10.2174/1573409915666190206142756] [PMID: 30727910]

[49] Mishra VR, Ghanavatkar CW, Mali SN, Qureshi SI, Chaudhari HK, Sekar N. Design, synthesis, antimicrobial activity and computational studies of novel azo linked substituted benzimidazole, benzoxazole and benzothiazole derivatives. Comput Biol Chem 2019; 78: 330-7.

[http://dx.doi.org/10.1016/j.compbiolchem.2019.01.003] [PMID: 30639681]

[50] Mishra VR, Ghanavatkar CW, Mali SN, Chaudhari HK, Sekar N. Synthesis, bioactivities, DFT and in-silico appraisal of azo clubbed benzothiazole derivatives. J Mol Struct 2019; 1192: 162-71. [http://dx.doi.org/10.1016/j.molstruc.2019.04.123]

[51] Mishra VR, Ghanavatkar CW, Mali SN, Chaudhari HK, Sekar N. Schiff base clubbed benzothiazole: synthesis, potent antimicrobial and MCF-7 anticancer activity, DNA cleavage and computational study. J Biomol Struct Dyn 2020; 38(6): 1772-85.

[http://dx.doi.org/10.1080/07391102.2019.1621213] [PMID: 31107179]

[52] Jadhav BS, Yamgar RS, Kenny RS, Mali SN, Chaudhari HK, Mandewale MC. Synthesis, In-Silico and biological studies of thiazolyl-2h-chromen-2-one derivatives as potent antitubercular agents. Curr Comput Aided Drug Des 2019; 15: 1.

[http://dx.doi.org/10.2174/1386207322666190722162100] [PMID: 
31438831]

[53] Kshatriya R, Kambale D, Mali SN, et al. Brønsted Acid Catalyzed Domino Synthesis of Functionalized 4H-Chromens and Their ADMET, Molecular Docking and Antibacterial Studies. ChemistrySelect 2019; 4: 7943-8.

[http://dx.doi.org/10.1002/slct.201901775]

[54] Shelke PB, Mali SN, Chaudhari HK, Pratap AP. Chitosan hydrochloride mediated efficient, green catalysis for the synthesis of perimidine derivatives. J Heterocycl Chem 2019.

[http://dx.doi.org/10.1002/jhet.3700]

[55] Anuse DG, Thorat BR, Sawant S, Yamgar RS, Chaudhari HK, Mali SN. Synthesis, SAR, Molecular Docking and Anti-Microbial Study of substituted N-bromoamido-2-aminobenzothiazoles. Curr Comput
Aided Drug Des 2019; 15: 1.

[http://dx.doi.org/10.2174/1573409915666190902143648] [PMID: 31475902]

[56] Jejurkar VP, Mali SN, Kshatriya R, Chaudhari HK, Saha S. Synthesis, Antimicrobial Screening and In Silico Appraisal of Iminocarbazole Derivatives. ChemistrySelect 2019; 4(32): 9470-5.

[http://dx.doi.org/10.1002/slct.201901890]

[57] Anuse DG, Mali SN, Thorat BR, Yamgar RS, Chaudhari HK Synthesis, SAR, In-Silico appraisal and Anti-Microbial Study of substituted 2-aminobenzothiazoles derivatives. Curr Comput Aided Drug Des 2019; 15: 1 .

[http://dx.doi.org/10.2174/1573409915666191210125647] [PMID: $31820704]$

\section{(C) 2020 Chopade et al.}

This is an open access article distributed under the terms of the Creative Commons Attribution 4.0 International Public License (CC-BY 4.0), a copy of which is available at: (https://creativecommons.org/licenses/by/4.0/legalcode). This license permits unrestricted use, distribution, and reproduction in any medium, provided the original author and source are credited. 